University of Nebraska - Lincoln

DigitalCommons@University of Nebraska - Lincoln

Faculty Publications: Department of

Entomology

Entomology, Department of

2010

Biotic and Abiotic Influences on Within-Plant Distribution of

Soybean Aphid (Hemiptera: Aphididae: Aphis glycines)

Tierney R. Brosius

University of Nebraska-Lincoln

Leon G. Higley

University of Nebraska-Lincoln, Ihigley1@unl.edu

Thomas E. Hunt

University of Nebraska-Lincoln, thunt2@unl.edu

Follow this and additional works at: https://digitalcommons.unl.edu/entomologyfacpub

Part of the Entomology Commons

Brosius, Tierney R.; Higley, Leon G.; and Hunt, Thomas E., "Biotic and Abiotic Influences on Within-Plant Distribution of Soybean Aphid (Hemiptera: Aphididae: Aphis glycines)" (2010). Faculty Publications:

Department of Entomology. 302.

https://digitalcommons.unl.edu/entomologyfacpub/302

This Article is brought to you for free and open access by the Entomology, Department of at DigitalCommons@University of Nebraska - Lincoln. It has been accepted for inclusion in Faculty Publications: Department of Entomology by an authorized administrator of DigitalCommons@University of Nebraska - Lincoln. 


\title{
Biotic and Abiotic Influences on Within-Plant Distribution of Soybean Aphid (Hemiptera: Aphididae: Aphis glycines)
}

\author{
Tierney R. Brosius, ${ }^{1}$ Leon G. Higley, ${ }^{1}$ and Thomas E. Hunt ${ }^{2}$
}

\begin{abstract}
The within-plant distribution of soybean aphid, Aphis glycines Matsumura has been attributed to various causes, yet it is unclear which factor or combination of factors most influence aphid within-plant distribution. Understanding soybean aphid distribution within the soybean canopy is important both in developing sampling programs and in evaluating injury. Because natural enemies have the potential to alter aphid dispersion, we examined how within-plant distribution of soybean aphid was influenced by different natural enemies. Field cages of different mesh diameters were used to exclude different sizes of natural enemies from aphid infested plots. Plots were surveyed and both natural enemy density and soybean aphid density, by strata, were recorded twice weekly. Cages were found to have minimal effect on temperature and soybean plant development. Aphid densities were significantly different each year among dates, treatments, and strata. In 2004 aphid densities were concentrated on the top part of the plant and in 2005 aphid densities were concentrated in the middle of the canopy. Treatments had significant impacts on aphid density in both years of the study. The total exclusion treatment had the highest aphid densities in both years. Treatment also had a significant effect on which stratum aphids were most commonly found. The factor that was found to best explain the differences in aphid distribution was the abundance of natural enemies, primarily Orius insidosus (Say). In treatments left exposed to natural enemies the percentage of the total aphid population was found lower in the canopy. It is clear that aphid densities and distributions are being affected by the presence of natural enemies. Understanding how natural enemies affect the distribution of this economically damaging aphid species is an important component of its management, specifically the development of accurate scouting protocols and pesticide efficiency.

KEY WORDS: aphid management, predator density, prey density, scouting protocols, soybean canopy
\end{abstract}

The within-plant distribution of an insect species is not random. Insects may disperse within a single plant to attain optimum nutrition (Leather and Dixon, 1981; Gianoli, 1999), to avoid natural enemies (Kareiva and Sahakian, 1990; Grevstad and Klepetka, 1992; Gonzales et al., 2001), and to avoid extreme temperatures in the canopy (Dixon and McKay, 1970; Wiktelius, 1987). Understanding within-plant distribution aids in the development of accurate scouting protocols, helps improve the efficiency of pesticide treatments, and is useful in characterizing the impact of aphid injury. Moreover, for arthropods that are relatively immobile while feeding, like mites, scales, or aphids, within-plant distribution may be especially important. The soybean aphid, Aphis glycines Matsumura, is a serious pest of soybean which was discovered in the Great Lakes region in the summer of 2000. This aphid's native range includes the tropical, subtropical, and temperate regions of Asia (Venette and Ragsdale, 2004; Wu et al., 2004). Currently, the soybean aphid is widely distributed across much of the northern soybean growing region of the United States, including Nebraska.

\footnotetext{
${ }^{1}$ School of Natural Resources, 706 Hardin Hall, University of Nebraska - Lincoln, Lincoln, Nebraska 68583-0987.

${ }^{2}$ Department of Entomology, 202 Entomology Hall, University of Nebraska - Lincoln, Lincoln, Nebraska 68583-0816.
} 
When soybean aphids first move into a field their distribution is often randomly scattered small colonies. The small colonies seen early in the year are the result of winged migrants that deposited nymphs (Ragsdale et al., 2004). This early colonization progresses rapidly with populations appearing randomly in the field. In contrast, colonization occurring later in the summer can show distinct edge effects with large colonies occurring in areas near windbreaks (Ragsdale et al., 2004). According to Ragsdale et al. (2004), soybeans are initially infested during the plant's vegetative growth and colonies are found at the tops of these plants. As plants begin to flower and form pods soybean aphids become more widely dispersed within the plant.

The within-plant distribution of the soybean aphid on soybean is currently believed to be connected to plant nutrition, plant growth, and temperature (Dixon and McKay, 1970; Hu et al., 1992; Van de Burg, 1997; Meyers et al., 2005; Desneux et al., 2006). Previous studies show that the distribution of aphids between and on host plants is often determined by the quality of plant material, including potassium (Meyers et al., 2005) and nitrogen (Hu et al., 1992). Hu et al. (1992) discovered a positive correlation between nitrogen content and the concentration of soybean aphids on the top leaves. Similarly, reproduction of aphids can depend upon the level of soluble nitrogen in their host plants (Dixon and McKay, 1970). Actively growing leaves serve as sinks for nitrogen and other nutrients in soybean plants (Staswick, 1994). Shusen et al. (1994) followed the distribution of soybean aphid on soybean plants through time. The results of their work suggest that the within-plant distribution of soybean aphid is the result of plant growth and weather.

It is clear that the nutrient quality of the plant can affect the distribution of soybean aphid, but the possible role of natural enemies on within-plant distribution of soybean aphid is still unclear. Natural enemies are capable of suppressing soybean aphid populations (Fox et al., 2004; Costamagna and Landis, 2006; Desneux et al., 2006; Brosius et al., 2007). The presence of natural enemies influences the withinplant distribution of many aphid species (Roitberg et al., 1979; Gonzales et al., 2001), and potentially soybean aphid (Rutledge and O'Neil, 2005). Therefore, it is reasonable to assume that the presence of natural enemies may have an effect on the distribution of soybean aphids found within the canopy.

As part of our examination of soybean aphid population dynamics, we directly considered the possible impact of biotic and abiotic factors on soybean aphid distribution in the soybean canopy. We examined distribution through time because canopy temperatures, nutritional quality of soybean leaves, natural enemy populations, and soybean aphid densities all vary through time. Given the complexity of potential interacting factors in altering soybean aphid distribution, we focused our examination on the role of natural enemies because we could directly manipulate natural enemy levels through our experimental design. Here, we report how natural enemies can alter soybean aphid within-plant distribution and identify potential interactions with other factors influencing within-plant distribution.

\section{Materials and Methods}

Most information on experimental design and methods is described in Brosius et al. (2007), which addresses the role of natural enemies on soybean aphid population dynamics. We have repeated much of that information below for clarity in reading 
and we offer some additional details relative to the objectives of this aspect of the overall experiment.

\section{Field Site}

Experiments were conducted at the University of Nebraska Haskell Agricultural Laboratory, Concord, Neb. Research plots were located in soybean fields under a two-year corn-soybean rotation with conventional tillage practices (2004 Colo silty clay loam, 0-2\% slope and in 2005 Baltic silty clay, 0\% slope). On 29 May 2004 and 23 May 2005, after double disking for seed bed preparation, fields were planted with soybean (Asgrow 2730) at 176,000 seeds/ha in $0.762 \mathrm{~m}$ rows. Experiments were conducted in these fields in individual plots, which were located at least $5 \mathrm{~m}$ from field borders to minimize edge effects. Glyphosate at 1.14 liter formulation/0.4 ha was applied twice each year. on 9 June and 28 June 2004, and on 27 May and 24 June 2005. Different fields were used each year of the study but they were within $1 \mathrm{~km}$ of each other.

\section{Study Design}

The experimental design was a randomized complete block, with treatments located in cages with different sized mesh coverings or uncaged soybeans of equal dimensions as cages (for the uncaged control treatment). Each cage represented one experimental unit, and there were four blocks of four treatments for a total of 16 experimental units. Each cage covered $1.8 \times 3.7 \mathrm{~m}$ ground area (centered over two rows), and cage supports $(2.5 \mathrm{~cm}$ diameter aluminum poles) were $2.5 \mathrm{~m}$ tall and extended into the ground $0.5 \mathrm{~m}$.

Custom field cages were placed over the aluminum supports, and consisted of nylon mesh of 1 or $2 \mathrm{~mm}$ squares and a full length zipper opening on one side. Specific treatments were: (1) uncaged control, staked $1.8 \times 3.7 \mathrm{~m}$ ground area; (2) caged (open) control, $2 \mathrm{~mm}$ mesh rolled up to allow complete access to canopy by all types of natural enemies; (3) partial exclusion cage $-2 \mathrm{~mm}$ mesh, intended to exclude large natural enemies (primarily predators great than $2 \mathrm{~mm}$ long; e.g., coccindelids, neuroptera larva, syrphid larvae); and (4) total exclusion cage $-1 \mathrm{~mm}$ mesh, intended to exclude all natural enemies, and if natural enemies were found in these cages they were manually removed.

In 2004 temperatures were recorded at ground level, mid-canopy, and immediately above the canopy with thermocouples (TMC6-HB, with $0^{\circ}-44^{\circ} \mathrm{C}$ range, $\pm 0.4^{\circ} \mathrm{C}$ accuracy at $20^{\circ} \mathrm{C}$, and $0.2^{\circ} \mathrm{C}$ resolution) attached to a Hobo ${ }^{\circledR} \mathrm{H} 8$ Outdoor/Industrial 4-Channel External Logger (Onset Computer Corp., Pocasset, MA). Probes were moved weekly to adjust for the growth of the soybean plant. Data were recorded from all treatments in all replications. however, one thermocouple failed in one replication of the caged (open) control treatment. Measurements were recorded at hourly. Temperatures were also recorded in 2005. however, an instrument failure at the end of the season resulted in loss of all 2005 temperature data.

Dates of all activities involving treatment establishment and assessment are listed in Brosius et al. 2007. Exclusion treatments (those with 1 or $2 \mathrm{~mm}$ mesh cages) were treated to remove pre-existing predators with the 0.052 liters ai/ha of malathion (which has a short half life of 1.5 day in sunlight [EPA 1991]). One week later, aphid treatments were artificially infested with healthy adult apterous aphids from a 
nearby field at 3 adult aphids/plant to simulate initial infestation rates observed locally. Natural aphid infestations were similar, but variable by field, in both years.

Aphid and natural enemy counts were made 2 to 3 times weekly on six plants chosen at random within each plot (in 2004, only four plants were sampled after August 11). Counts included nymphs, apterous adults, and pterous adults, and natural enemies identified to the lowest possible taxon .. Aphid number, and natural enemy type and number were recorded for individual leaves starting from the base of the plant. Each leaf was designated by counting the nodes from the base of the plant (the cotyledonary node $=$ node 0 ) in the same method used to determine the vegetative stage of the plant. Aphids were counted individually until their numbers became too large ( $>100 /$ leaf), and then were counted by tens or hundreds. Accuracy of counts by tens or hundreds was tested on each sampling date by directly comparing counts of all individuals on at least one leaf in each plot (16 total), until counts by tens or hundreds were within $10 \%$ of counts of all individuals. .Vegetative and reproductive stages (Ritchie et al., 1995) of the soybean plants . were recorded on each sampling date.

\section{Data Analysis}

Main effects consisted of strata (different groups of nodes in the soybean canopy) and treatment (cages used to exclude different types of natural enemies). For strata, data were collected for each node and combined by plant into 3 strata with equal numbers of nodes: bottom, middle, and top., For treatments, our a priori comparisons of interest were: (1) uncaged control versus caged (open) control, to identify potential cage effects; and (2) uncaged control (all natural enemies) versus partial exclusion cage versus total exclusion cage. Data were analyzed by analysis of variance through PROC MIXED (SAS Institute 9.1, 2002), with treatment comparisons by protected LSD at the 0.05 level, unless otherwise indicated.

For analysis across dates, a repeated measures analysis was conducted with PROC MIXED, using sampling date as the whole plot. Because appropriate use of PROC MIXED for repeated measures analysis requires estimation of the covariance structure (variance components), we iteratively tested different covariance structures to identify the structure with the lowest fit statistics (Akaike's Information Criterion or AIC). The lowest AIC was achieved with an antedependent structure, which we used in subsequent repeated measures analysis under PROC MIXED (Littell et al., 1996). To determine if the treatment effect was independent of density we ran an analysis of covariance following the procedure outlined in SAS Systems for Mixed Models (Littell et al., 1996).

Degree days were calculated by hourly intervals and accumulations determined by summing across hours and days. Calculations were based on a minimum developmental threshold for A. glycines of $8.6^{\circ} \mathrm{C}$ (McCornack et al., 2004), and hourly degree days were calculated as the area of a trapezoid, specifically:

$$
\left(\left(\frac{(\text { HourlyTemperature } 1+\text { HourlyTemperature } 2)}{2}\right)-8.6^{\circ} \mathrm{C}\right) *(1 \text { hour })
$$

Accumulated degree days were determined from 27 August 2004 to 16 September 2004, and no temperatures spanned the developmental minimum over these dates. 
Table 1. Repeated measures analysis of variance for soybean canopy stratum and treatment effects on soybean aphid density (\#/stratum, with an equal number of nodes per stratum) in 2004 and 2005.

\begin{tabular}{|c|c|c|c|c|c|c|c|c|c|c|}
\hline \multicolumn{6}{|c|}{2004} & \multicolumn{5}{|c|}{2005} \\
\hline \multirow[b]{2}{*}{ Stratum } & \multicolumn{5}{|c|}{ Treatment Means (SE in parentheses) } & \multicolumn{5}{|c|}{ Treatment Means (SE in parentheses) } \\
\hline & $\begin{array}{c}\text { Caged (Open) } \\
\text { Control }\end{array}$ & $\begin{array}{r}\text { Par } \\
\text { Exclu }\end{array}$ & & Tot & Exclusion & Stratum & \multicolumn{2}{|c|}{$\begin{array}{l}\text { Caged (Open) } \\
\text { Control }\end{array}$} & $\begin{array}{c}\text { Partial } \\
\text { Exclusion }\end{array}$ & Total Exclusion \\
\hline Top & $42.68(2.64)$ & 119.89 & 27) & 145 & $2(8.63)$ & Top & 0.72 & $0.11)$ & $1.59(0.14)$ & $73.62(4.1)$ \\
\hline Middle & $30.36(2.26)$ & 89.78 & 89) & & $2(6.04)$ & Middle & 1.26 & $0.11)$ & $3.38(0.29)$ & $96.92(5.34)$ \\
\hline Bottom & $0.36(0.08)$ & 1.35 & 89) & & $1(0.48)$ & Bottom & 0.09 & $0.02)$ & $0.15(0.03)$ & $2.8(0.082)$ \\
\hline \multicolumn{11}{|c|}{ ANOVA } \\
\hline \multicolumn{2}{|c|}{ Effect } & $F$ Value & \multicolumn{2}{|c|}{ d.f. } & $\operatorname{Pr}>F$ & \multicolumn{2}{|c|}{ Effect } & $F$ Value & d.f. & $\operatorname{Pr}>F$ \\
\hline \multicolumn{2}{|l|}{ Trt } & 46.32 & \multicolumn{2}{|c|}{2,6} & $<0.0001$ & \multicolumn{2}{|l|}{ Trt } & 250.16 & 2,6 & $<0.0001$ \\
\hline \multicolumn{2}{|l|}{ Stratum } & 164.49 & \multicolumn{2}{|c|}{2,18} & $<0.0001$ & \multicolumn{2}{|c|}{ Stratum } & 67.58 & 2,18 & $<0.0001$ \\
\hline \multicolumn{2}{|c|}{ Trt*Stratum } & 17.01 & \multicolumn{2}{|c|}{4,18} & $<0.0001$ & \multicolumn{2}{|c|}{ Trt*Stratum } & 59.54 & 4,18 & $<0.0001$ \\
\hline \multicolumn{2}{|l|}{ Days } & 50.81 & \multicolumn{2}{|c|}{11,297} & $<0.0001$ & \multicolumn{2}{|l|}{ Days } & 37.38 & 9,261 & $<0.0001$ \\
\hline \multicolumn{2}{|c|}{ Days*Trt } & 4.87 & \multicolumn{2}{|c|}{22,297} & $<0.0001$ & \multicolumn{2}{|c|}{ Days*Trt } & 36.23 & \multirow[t]{2}{*}{18,261} & $<0.0001$ \\
\hline \multicolumn{2}{|c|}{ Days*Stratum } & 15.27 & \multicolumn{2}{|c|}{22,297} & $<0.0001$ & & & & & \\
\hline \multicolumn{2}{|c|}{ Days*Stratum } & 9.07 & \multicolumn{2}{|c|}{18,261} & $<0.0001$ & & & & & \\
\hline \multicolumn{2}{|c|}{ Days*Trt*Stratum } & 1.72 & 44 & 297 & $<0.0001$ & & & & & \\
\hline Days* $\mathrm{Tr}_{1}$ & $t *$ Stratum & 8.76 & 36 & 261 & $<0.0001$ & & & & & \\
\hline
\end{tabular}

Where recording thermocouples failed during this period, accumulated degree days were treated as missing data points.

\section{Results and Discussion}

\section{Cage Effects}

No significant differences in aphid density were observed between caged and uncaged controls. As indicated in the methods, the caged (open) control treatments were open and did not exclude aphids or predators; obviously closed cage treatments (which excluded natural enemies) did influence aphid densities. Temperatures across strata did not significantly differ between treatments in 2004 (2004: $F_{3,11}=0.76$, $P>F=0.5391)$ ) nor was there a significant treatments by stratum interaction (2004: $F_{6,17}=1.69, P>F=0.1830$ ); therefore, cages had no significant impact on temperatures. We found no significant treatment differences in soybean reproductive stages (2004: $\left.F_{3,9}=0.15, P>F=0.9263 ; 2005: F_{3,9}=2.30, P>F=0.1455\right)$ or vegetative stages (2004: $F_{3,9}=1.66, P>F=0.2436 ; 2005: F_{3,9}=2.64, P>F=$ 0.1130). Because no significant cage effects were observed the uncaged control was not further considered.

\section{Strata Effects}

The total number of nodes on plants ranged between 12 and 17 across dates and years, so each stratum (top, middle, and bottom) represents a combination of 4 to 6 nodes. Aphid densities were significantly different each year among dates, treatments, and strata (Table 1). In 2004 the largest aphid density was found in the top stratum of the plant on almost every date surveyed across treatments (Fig. 1). In 2005, however, a different pattern of aphid distribution was observed (Fig. 1), with a greater proportion 


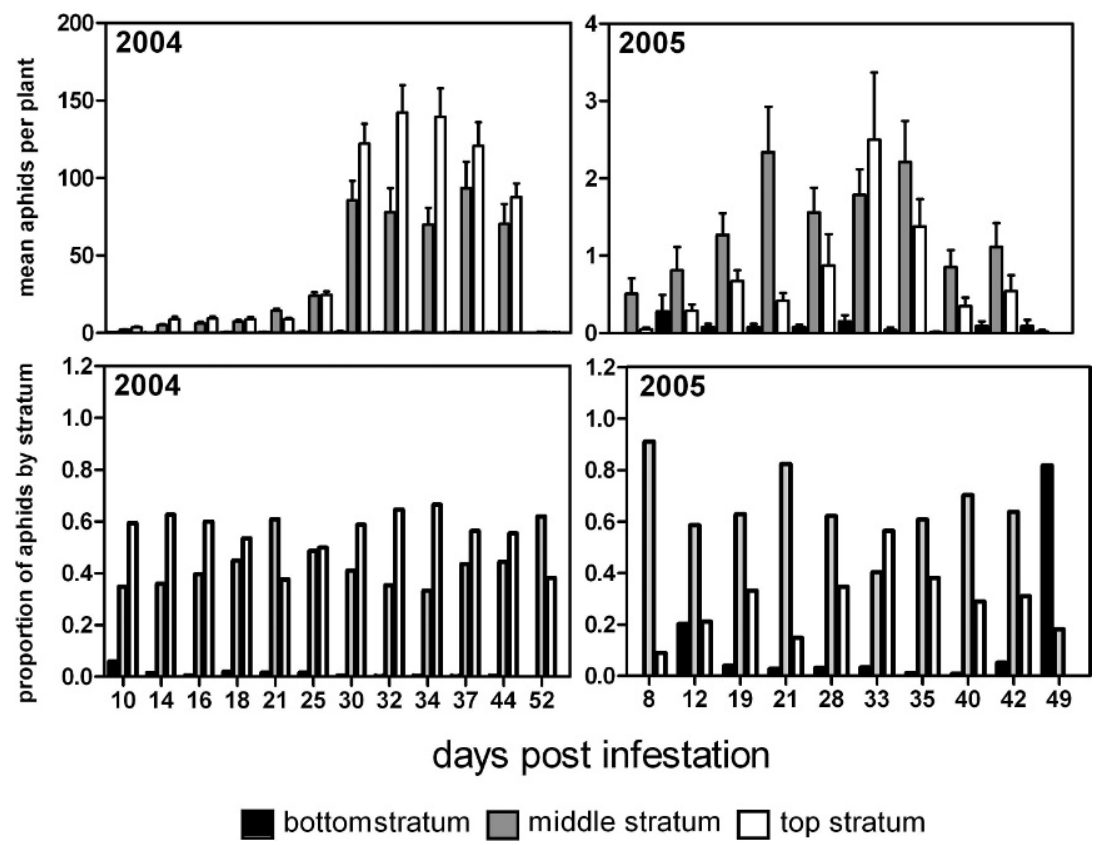

Fig. 1. The average aphid density per plant and the proportion of aphids found within each stratum in 2004 and 2005 in the caged (open) control treatments.

of aphids in the middle stratum. Were stratum differences in aphid distribution associated with temperature differences by stratum? Although we observed no significant treatment effects on temperature, as expected, temperatures were significantly different between strata $\left(F_{2,17}=30.45, P>F<0.0001\right)$, with higher temperatures associated with upper strata. Although we observed increases in temperature with height, the mean differences between strata were slight (lower stratum $17.78^{\circ} \mathrm{C}$ (s.e. 0.04 ); middle stratum $17.94^{\circ} \mathrm{C}$ (s.e. 0.04 ), upper stratum $18.11^{\circ} \mathrm{C}$ (s.e. 0.05), with the total mean temperature difference of only $0.4^{\circ} \mathrm{C}$. Temperature can affect insect distribution within a single plant (Dixon and McKay, 1970; Wiktelius, 1987) and soybean aphids, in the lab, perform better under more mild temperatures (ca. $<24^{\circ} \mathrm{C}$ ) (McCornack et al., 2004). However, in 2004 we found more aphids were found in the upper canopy that middle and lower. Similarly, if temperature drove aphid distribution in our study, we should observe a treatment by stratum interaction in temperature. We examined this relationship with both mean temperatures and calculated soybean aphid degree days, but neither of these interactions were significant (temperature $\times$ strata, $F_{6,17}=1.69, P>F<0.1830$; temperature $\times$ degree days, $F_{4,15}$ $=2.15, P>F<0.1215$ ). Finally, we regressed temperature and degree days with aphid densities, but did not find a significant relationship. Consequently, temperature does not account for difference in aphid dispersion by stratum.

Temperature might be thought to explain differences in distribution between years in our study, but because of the similar number of aphids found in the total exclusion treatments (Table 2) for both years of the study we can determine that temperature was not the only factor acting on aphid densities. The small differences seen in temperatures between years are not enough to explain the large differences in aphid 
Table 2. Average number of aphids and natural enemies/ plant by year and by treatment (standard error in parentheses).

\begin{tabular}{|c|c|c|c|c|c|c|}
\hline \multirow[b]{2}{*}{ Mean \#/plant } & \multicolumn{3}{|c|}{2004} & \multicolumn{3}{|c|}{2005} \\
\hline & $\begin{array}{c}\text { Total } \\
\text { Exclusion }\end{array}$ & $\begin{array}{l}\text { Partial } \\
\text { Exclusion }\end{array}$ & $\begin{array}{c}\text { Caged (Open) } \\
\text { Control }\end{array}$ & $\begin{array}{c}\text { Total } \\
\text { Exclusion }\end{array}$ & $\begin{array}{l}\text { Partial } \\
\text { Exclusion }\end{array}$ & $\begin{array}{c}\text { Caged (Open) } \\
\text { Control }\end{array}$ \\
\hline Soybean Aphid & 973.31 (98.71) & $925.9(105.75)$ & $523.57(56.5)$ & $818.17(75.2)$ & $22.86(2.8)$ & $7.17(0.65)$ \\
\hline Predators & $0.04(0.01)$ & $0.8(0.4)$ & $0.79(0.29)$ & $0.04(0.02)$ & $0.03(0.01)$ & $0.12(0.03)$ \\
\hline Parasitoids & $0.85(0.23)$ & $2.25(0.49)$ & $0.28(0.07)$ & $0.0(0.0)$ & $0.05(0.02)$ & $0.0(0.0)$ \\
\hline O. insidiosus & $0.01(0.01)$ & $0.18(0.03)$ & $0.36(0.05)$ & $0.2(0.04)$ & $0.56(0.07)$ & $0.47(0.06)$ \\
\hline
\end{tabular}

densities among caged and control treatments between years. By the lack of differences seen in plant quality and aphid abundance between the caged (open) and un-caged control, we were able to determine that light and relative humidity did not significantly affect the treatments.

The factor that best explains differences in aphid distribution between years is the presence of natural enemies, primarily $O$. insidiosus. In the absence of natural enemies in 2004, aphids were found in high abundance in the top of the soybean canopy. In treatments left exposed to natural enemies, the percentage of the total aphid population was lower in the top of the canopy. Higher levels of natural enemies found in 2005 may have contributed to the difference in distribution between years. Mean numbers of $O$. insidiosus in the open treatments in 2004 were $0.15 /$ plant, in contrast to 2005 where the average number of $O$. insidiosus was $0.46 /$ plant.

Orius insidiosus may have worked in conjunction with the higher temperatures in 2005 to prevent soybean aphid colonization. Although higher temperatures did not suppress the population growth of the aphids in the total exclusion cage in 2005, we can not disregard the potential interaction between natural enemies and temperatures in preventing successful aphid colonization.

\section{Stratum by Time}

A significant interaction was found between stratum and day (Table 1). This interaction . is likely to be caused by the establishment of the aphid on the host plant and redistribution because of host plant conditions linked to phenological events (specifically, changes in the nutritional quality of soybean leaves). Aphid densities are highly dependent on nutrient availability of the plant (Kennedy et al., 1950; Leather and Dixon, 1981; Gianoli, 1999).

Shusen et al. (1994) found that soybean aphid concentrated on the new leaves when they initially migrated to the soybean field then moved to the lower parts of the plant as temperatures rose, indicating that the movement is a combination of temperature and plant quality. Additional evidence suggests that nutrient availability is responsible for high densities of aphids in the top of the plant. Each year, at the start of our study, soybean plants were at reproductive stage R3, or beginning pod formation. At R3, the concentration of nitrogen moves from the leaves to the developing pods (Harper, 1987). The highest concentration of nitrogen, which has been linked to increases in aphid density (Han, 1997), is not found in the leaves during this stage of development. Thus, leaf nitrogen levels were decreasing during our study as leaf nitrogen was mobilized into pods and seeds. Because pod 


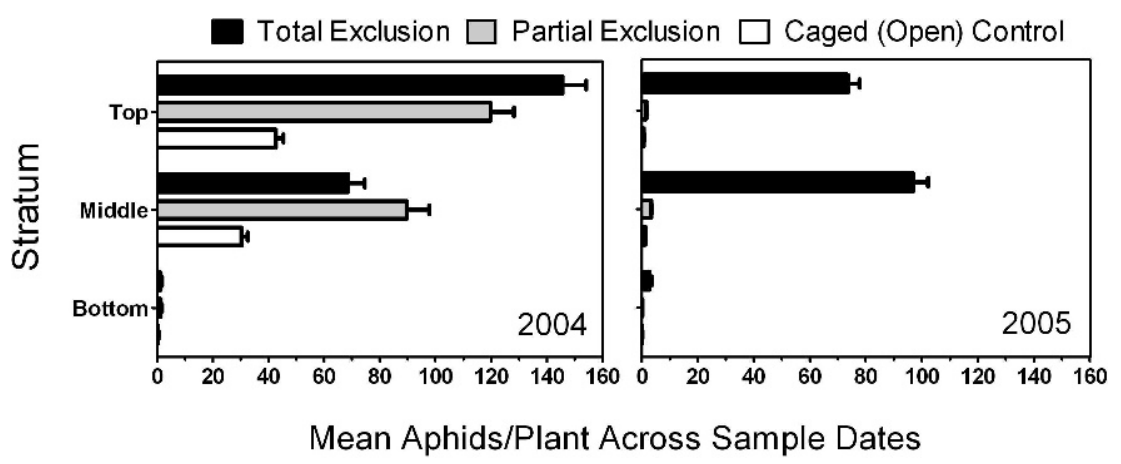

Fig. 2. The average aphid density across days within each stratum for each treatment in 2004 and 2005.

formation and seed fill proceeds from the bottom of the plant upwards, higher nitrogen levels would be associated with more apical leaves.

\section{Treatment Effects}

Treatment effects represent the differences between control, partial exclusion, and total exclusion cages on aphid densities. This design uses cages to exclude different natural enemies, so treatments can be regarded as reflective of conditions approximating all natural enemies (control), primarily small predators and parasitoids (partial exclusion (less than $2 \mathrm{~mm}$ long; e.g., parasitic hymenopterans, anthocorids, predacious thysanopterans), and no natural enemies (total exclusion). There was a significant treatment effect in both years $\left(2004 F_{3,9}=11.14, P>F=\right.$ $\left.0.0022,2005 F_{3,9}=181.65, P>F=0.0001\right)$. In 2004 the highest average number of aphids per plant (3091) was found in the total exclusion treatments, next in the partial exclusion treatments (2826), and least in the no exclusion treatment (932) (Brosius et al., 2007). In 2005, the number of aphids found in the total exclusion treatment (2608) was dramatically higher than the numbers the no exclusion (21) and the partial exclusion treatments (55) (Brosius et al., 2007). These results corresponded with differences in natural enemy densities among treatments (Table 2).

\section{Treatment by Stratum}

The treatment by stratum interaction on aphid density was significant in both years (Table 1, Fig. 2). So few aphids occurred in the bottom stratum in either year that no treatment differences were observed. However, in the middle and top strata, aphid densities were higher in the partial and total exclusion treatments than in the control. Moreover, proportionally fewer aphids occurred in the top stratum of the partial exclusion treatment than in the total exclusion treatment. This result indicates that the presence of natural enemies altered aphid distribution either by reducing aphid numbers in the upper stratum or changing aphid behavior to avoid predators and parasitoids by moving from upper to middle stratum of the soybean canopy. In 2005, the control and partial exclusion treatments were not significantly different from each other in any strata but both were significantly lower than the total exclusion in the same strata (Fig 1). 


\section{Stratum by Treatment by Time}

The effect of natural enemies on aphid dispersion varies through time. The complexity of the interactions between nutrition, natural enemies, temperatures, and aphid biology make it difficult to clearly illustrate the three way interaction. A better understanding of how aphids are following the availability of nitrogen and how they are being affected by temperatures is necessary to fully comprehend how all of these factors are interacting. It is clear, however, that aphid densities and distributions are being affected by the presence of natural enemies. If natural enemies are effective at reducing aphid populations and if predation causes aphids to produce an alarm pheromone as indicated by Butler and O'Neil (2006), it is logical to assume that distribution is connected to the presence of natural enemies.

\section{Implications for Aphid Management}

Scouting recommendations currently suggest looking on the upper two or three trifoliolate leaves and stems for aphids, suggesting that aphids are more likely to concentrate in the plant terminal (Rice et al., 2005). Field observations for both 2004 and 2005 showed that after the infestation of the top soybean trifoliolate, aphid colonies were commonly found in the middle of the soybean canopy. Not until populations began to increase did aphid densities concentrate at the top of the plant. It remains unclear if these observations are related to the plant stage, lateness of infestation, or the temperatures during infestation. Our research supports the scouting recommendation that concentrates on the plant terminal. These observations do show, however, that if the scouting objective is to detect the presence of aphids in the field, looking at the top of the plant may not always be effective.

\section{Acknowledgments}

We thank Gerald Echtenkamp and Stephen Spomer for their assistance with experiment, and Dr. Erin Blankenship for statistical advice. This work was supported by the Nebraska Agricultural Experiment Station (Projects NEB-17-078 and NEB-17-080), and by 2 grants from the Nebraska Soybean Board.

\section{Literature Cited}

Brosius, T. R., L. G. Higley, and T. E. Hunt. 2007. Population dynamics of soybean aphid (Aphis glycines) and biotic mortality at the edge of its range. Journal of Economic Entomology 100:1268-1275.

Butler, C. D., and R. J. O'Neil. 2006. Defensive response of soybean aphid (Hemiptera: Aphididae) to predation by insidious flower bug (Hemiptera: Anthocoridae). Annals of the Entomological Society of America 99:317-320.

Costamagna, A. C., and D. A. Landis. 2006. Predators exert top-down control of soybean aphid across a gradient of agricultural management systems. Journal of Applied Ecology 16:1619-1628.

Desneux, N., R. J. O’Neil, and H. J. S. Yoo. 2006. Suppression of population growth of the soybean aphid, Aphis glycines Matsumura, by predators: the identification of a key predator and the effects of prey dispersion, predator abundance, and temperature. Environmental Entomology 35:1342-1349.

Dixon, A. F. G. 2000. Insect Predator-Prey Dynamics, Ladybird Beetles and Biological Control. Cambridge University Press, Cambridge, England.

Dixon, A. F. G., and S. McKay. 1970. Aggregation in the sycamore aphid Drepanosiphum platanoides (Schr.) (Hemiptera: Aphididae) and its relevance to the regulation of population growth. Journal of Animal Ecology 39:439-454. 
Fox, T. B., D. A. Landis, F. F. Cardoso, and C. D. DiFonzo. 2004. Predators suppress Aphis glycines Matsumura population growth in soybean. Environmental Entomology 33:608-618.

Gianoli, E. 1999. Within-plant distribution of Rhopalosiphum padi on wheat seedlings is affected by induced responses. Entomologia Expermentalis Applicata 93:220-230.

Gonzales, W. L., E. Gianoli, and H. M. Niemeyer. 2001. Plant quality vs. risk of parasitism: within-plant distribution and performance of the corn leaf aphid, Rhopalosiphum maidis. Agricultural and Forest Entomology 3:29-33.

Grevstad, F. S., and B. W. Klepetka. 1992. The influence of plant architecture on the foraging efficiencies of a suite of ladybird beetles feeding on aphids. Oecologia 92:399-404.

Harper, J. E. 1987. Nitrogen metabolism. In J. R. Wilcox (ed.). Soybeans: Improvement, pp. 510-513. Production, and Uses, Madison, WI.

Han, X. 1997. Population dynamics of soybean aphid Aphis glycines and its natural enemies in fields. Hubei Agricultural Science 2:22-24.

Hu, Q., W. Q. Zhang, Y. X. Yao, and S. Q. Yan. 1992. Relationship between nitrogen content in soybean leaves and occurrence of Aphis glycines. Journal of Jilin Agricultural University 14:103-104.

Kareiva, P., and R. Sahakian. 1990. Tritrophic effects of a simple architectural mutation in pea plants. Nature 345:433-434.

Kennedy, J. S., A. Ibbotson, and C. O. Booth. 1950. The distribution of aphid infestation in relation to leaf age. I. Myzus persicae (Sulz.) and Aphis fabae Scop. on spindle trees and sugar-beet plant. Annals of Applied Biology 37:651-679.

Leather, S. R., and A. F. G. Dixon. 1981. The effect of cereal growth stage and feeding site on the reproductive activity of the bird-cherry aphid, Rhopalosiphum padi. Annals of Applied Biology 97:135-141.

Littell, R. C., G. A. Milliken, W. W. Stroup, and R. D. Wolfinger. 1996. SAS Systems for Mixed Models. SAS Institute Inc., Cary, NC.

Myers, S. W., C. Gratton, R. P. Wolkowski, D. B. Hogg, and J. L. Wedberg. 2005. Effect of soil potassium availability on soybean aphid (Hemiptera: Aphididae) population dynamics and soybean yield. Journal of Economic Entomology 98:113-120.

McCornack, B. P., D. W. Ragsdale, and R. C. Venette. 2004. Demography of soybean aphid (Homoptera: Aphididae) at summer temperatures. Journal of Economic Entomology 97:857-861.

Ragsdale, D. W., D. J. Voegtlin, and R. J. O’Neil. 2004. Aphis glycines biology in North America. Annals of the Entomological Society of America 97:204-208.

Rice, M. E., M. O'Neal, and P. Pedersen. 2005. Soybean aphids in Iowa. Iowa State University Extension. (http://www.ent.iastate.edu/soybeanaphid/files/Aphids.SP247_0.pdf)

Roitberg, B. D., J. H. Myers, and B. D. Frazer. 1979. The influence of predators on the movement of apterous pea aphid between plants. Journal of Animal Ecology 48:111-122.

Rutledge, C. E., and R. J. O’Neil. 2005. Orius insidiosus (Say) as a predator of the soybean aphid, Aphis glycines Matsumura. Biological Control 33:56-64.

SAS Institute. 2002. PROC user's manual, Version 9.1. SAS Institute, Cary, NC.

Shusen, S., Y. Boren, L. Dianshen, and Y. Yanjie. 1994. Study on space dynamics of a natural population of Aphis glycines Matsumura. Journal of Jilin Agricultural University 16:75-79.

Staswick, P. E. 1994. Storage proteins of vegetative tissues. Annual Review of Plant Physiology and Plant Molecular Biology 45:303-322.

Van den Berg, H., D. Ankasah, A. Muhammad, R. Rusli, H. A. Widayanto, H. B. Wirasto, and I. Yully. 1997. Evaluating the role of predation in population fluctuations of the soybean aphid Aphis glycines in farmers' fields in Indonesia. Journal of Applied Ecology 34:971-984.

Venette, R. C., and D. W. Ragsdale. 2004. Assessing the invasion by soybean aphid (Homoptera: Aphididae) where will it end? Annals of the Entomological Society of America 97:219-226.

Wiktelius, S. 1987. Distribution of Rhopalosiphum padi (Homoptera: Aphididae) on spring barley plants. Annals of Applied Biology 110:1-7.

Wu, Z., D. Schenk-Hamlin, W. Zhan, D. W. Ragsdale, and G. E. Heimpel. 2004. The soybean aphid in China: A historical Review. Annals of the Entomological Society of America 87:209-218. 